\title{
Biochemical mechanisms underlying atherogenesis
}

\author{
P.V.L.N. Srinivasa Rao,V.S. Kiranmayi \\ Department of Biochemistry, Sri Venkateswara Institute of Medical Sciences, Tirupati
}

\begin{abstract}
Atherosclerosis remains one of the major causes of death and premature disability in developed countries. Though atherosclerosis was formerly considered a bland lipid storage disease, substantial advances in basic and experimental sciences have illuminated the role of endothelium, inflammation and immune mechanisms in its pathogenesis. Current concept of atherosclerosis is that of a dynamic and progressive disease arising from injury to endothelium, also known as endothelial dysfunction and an inflammatory response to that injury. The lesions of atherosclerosis occur principally in large and medium sized arteries. Atherosclerosis affects various regions of the circulation preferentially and can lead to ischemia of heart, brain or extremities resulting in infarction.

This produces distinct clinical manifestations depending on the vessel involved. Several predisposing factors to cardiovascular diseases such as diabetes mellitus, hypertension, obesity, infections act as triggers to the development of atherosclerosis by causing endothelial dysfunction and/or promoting inflammatory response. The evolution of pathogenetic mechanisms has passed through various directions such as oxidative stress, inflammation and immune responses. It is now known that all these are not acting independently but are interrelated and getting unified in the current concept of atherogenesis. The following discussion aims at providing an insight into these developments which can help in a better comprehension of the disease and management of its clinical complications.
\end{abstract}

Key words: Atherogenesis, Endothelial dysfunction, Oxidative stress, Inflammation

Srinivasa Rao PVLN, Kiranmayi VS. Biochemical mechanisms underlying atherogenesis. J Clin Sci Res 2012;1:24-34.

Atherosclerosis remains one of the major causes of death and premature disability in developed countries. Current predictions estimate that by the year 2020, cardiovascular diseases, notably atherosclerosis will become the leading global cause of total disease burden. ${ }^{1}$ Many generalized or systemic risk factors predispose to its development.

Atherosclerosis affects various regions of the circulation preferentially and produces distinct clinical manifestations depending on the vessel involved. This can lead to ischemia of heart, brain or extremities resulting in infarction. Though, atherosclerosis was formerly considered a bland lipid storage disease, substantial advances in basic and experimental sciences have illuminated the role of endothelium, inflammation and immune mechanisms. ${ }^{2}$

Current concept of atherosclerosis is that of a dynamic and progressive disease arising from injury to endothelium, also known as endothelial dysfunction and an inflammatory response to that injury. ${ }^{3}$

\section{THE PROCESS OF ATHEROGENESIS}

\section{Endothelial dysfunction}

Vascular endothelium is regarded as a functional barrier between vessel wall and blood stream. Studies have found that besides being an inert barrier, endothelium has several other important functions such as coagulation, fibrinolysis, vascular tone, growth and immune response. Endothelial status may be regarded as an integrated index of all atherogenic and atheroprotective factors. Vascular homeostasis is maintained by a balance between endothelium derived relaxing and contracting factors. Disruption of this balance causing injury is called endothelial dysfunction. This is mediated by various risk factors and results in increased susceptibility of the vasculature to atheroma formation. Thus, the term endothelial dysfunction implies diminished production or bioavailability of nitric oxide (NO), the endothelium derived relaxing factor. ${ }^{4}$ Endothelial dysfunction promotes inflammation within the vessel wall, thus 
setting the stage for the initiation and progression of an atherosclerotic lesion.

\section{Formation of foam cells}

Initiation of inflammatory response involves increased expression of adhesion molecules and chemoattractants (Table 1) that promote the adherence of cells to endothelium that include platelets and monocytes. When activated, platelets release their granules, which contain cytokines and growth factors that, together with thrombin, may contribute to the migration and proliferation of smooth muscle cells and monocytes, formation of prostaglandins such as thromboxane A2, one of the most potent vasoconstricting and plateletaggregating substances known, or into leukotrienes, which can amplify the inflammatory response. ${ }^{5}$ Several mediators such as pro inflammatory cytokines, acute phase proteins like the C-reactive protein (CRP), protease activated receptor signaling, oxidized low density lipoprotein (OxLDL) uptake via lectin-like ox-LDL receptor-1 (LOX-1), CD40 / CD40 ligand interactions also induce the expression of adhesion molecules. ${ }^{6-10}$ The monocytes adhered to the endothelium migrate across the endothelium. Once within the arterial intima, the monocytes develop into macrophages and begin to express scavenger receptors such as Scavenger receptor A (SR-A), LOX-1, which internalize the modified lipoproteins. ${ }^{11,12}$ This gives rise to lipid laden macrophages, known as foam cells, which are characteristic of early atherosclerotic lesions. These foam cells within the atheroma begin to secrete proinflammatory cytokines which further maintain a chemotactic stimulus for adherent leucocytes, augment the expression of SR-A and promote macrophage replication (Figure 1). ${ }^{13}$

\section{Progression of inflammation to plaque formation and expansion}

The progression of fatty streak into atheromatous plaque occurs by the proliferation of smooth muscle cells (SMC), their migration towards intima and synthesis of colla- gen. Continued release of the inflammatory response molecules by the activated T-cells, endothelial cells and foam cells perpetuates inflammation, lipid accumulation within the atheroma and smooth muscle cell activity. $^{3,14}$ This also result in increased migration and multiplication of macrophages and lymphocytes. Activation of these cells leads to the release of hydrolytic enzymes, cytokines, chemokines, and growth factors, which can induce further damage and eventually lead to focal necrosis. Thus, cycles of accumulation of mononuclear cells, migration and proliferation of smooth muscle cells and formation of fibrous tissue lead to further enlargement and restructuring of the lesion, so that it becomes covered by a fibrous cap that overlies a core of lipid and necrotic tissue $\mathrm{e}^{2,15}$ (Figure 2). This can cause obstruction of vascular lumen, which is clinically manifested based on the site. For e.g., lesion in coronary arteries causing reduction in blood flow manifesting as angina.

\section{Fate of atheromatous plaque}

Inflammatory response also plays a role in the development of complications of atheromatous plaque, i.e., rupture followed by thomboembolic phenomenon which is mainly responsible for acute complications of atherogenesis like stroke and myocardial Infarction. The activated macrophages produce proteolytic enzymes which degrade the collagen and weaken the protective fibrous cap. This, coupled with the production of tissue factor by macrophages provides a prothrombotic mileu leading to thrombosis when plaque ruptures. ${ }^{2}$

Thus, atherosclerosis can be considered to be a form of chronic inflammation resulting from interaction between 
modified lipoproteins, monocyte derived macrophages and $\mathrm{T}$-cells that migrate from blood and the normal cellular elements of the arterial wall.

\section{Site of development}

The lesions of atherosclerosis occur principally in large and medium sized arteries. The nature of the flow, i.e., shear stress or turbulence, appears to be important in determining where the lesions occur. Changes in flow alter the expression of molecules involved in atherogenesis. Rolling and adherence of monocytes and $\mathrm{T}$-cells occur more at these sites and appear to be critical in determining the sites of lesions. $^{16}$

TRIGGERS FOR ENDOTHELIAL DYSFUNCTION / INFLAMMATION

Various predisposing factors to cardiovas- cular diseases act as triggers to the development of atherosclerosis by causing endothelial dysfunction and/or promoting inflammatory response. These include diabetes mellitus, hypertension, obesity and infections. Hypertension contributes to endothelial dysfunction through elevated concentrations of angiotensin II, which increases smooth muscle lipoxygenase activity, inflammation and the oxidation of LDL. ${ }^{16}$ Diabetes is yet another risk factor for atherosclerosis. The hyperglycemia associated modification of macromolecules forming advance glycation end products (AGE), ${ }^{17}$ augment the production of proinflammatory cytokines and other inflammatory pathways in vascu-

Table 1: Over view of molecules involved in atherogenesis

\begin{tabular}{|c|c|}
\hline Molecule & Nature of function \\
\hline \multirow{2}{*}{ Selectin-E, selectin-L, selectin-P } & Up regulation of leukocyte and endothelial adhesion molecules \\
\hline & Platelet adhesion and aggregation \\
\hline Integrins & $\begin{array}{l}\text { Up regulation of leukocyte adhesion molecules, platelet } \\
\text { adhesion and aggregation }\end{array}$ \\
\hline Interleukins (IL-1, IL-2, IL-8) & $\begin{array}{l}\text { Migration of leukocytes into arterial wall, T-cell activation, } \\
\text { formation of foam cells, formation of fibrous cap }\end{array}$ \\
\hline $\begin{array}{l}\text { Adhesion molecules (platelet endothelial cell } \\
\text { adhesion molecule, ICAM-1, VCAM-1) }\end{array}$ & Up regulation of leukocyte and endothelial adhesion molecules \\
\hline Monocyte chemotactic protein-1 & $\begin{array}{l}\text { Migration of leukocytes into arterial wall macrophage } \\
\text { accumulation }\end{array}$ \\
\hline Macrophage colony stimulating factor & $\begin{array}{l}\text { Migration of leukocytes into arterial wall, formation of foam } \\
\text { cell, macrophage accumulation }\end{array}$ \\
\hline Platelet derived growth factor & $\begin{array}{l}\text { Migration of leukocytes into arterial wall, Stimulation of smooth } \\
\text { muscle migration, formation of fibrous cap }\end{array}$ \\
\hline Tumour necrosis factor- $\alpha$ & T-cell activation, formation of foam cell formation of fibrous cap \\
\hline Transforming growth factor $-\beta$ & Stimulation of smooth muscle migration formation of fibrous cap \\
\hline Osteopontin & Migration of leukocytes into arterial wall formation of fibrous cap \\
\hline Fibroblast growth factor II & Stimulation of smooth muscle migration \\
\hline $\begin{array}{l}\text { Granulocyte macrophage colony stimulating } \\
\text { factor }\end{array}$ & T-cell activation \\
\hline Fibrin, thromboxane, tissue factor & Platelet adhesion and aggregation \\
\hline
\end{tabular}

IL = interleukin; ICAM-1= intercellular adhesion molecule 1; VCAM-1 = vascular cell adhesion molecule 1 


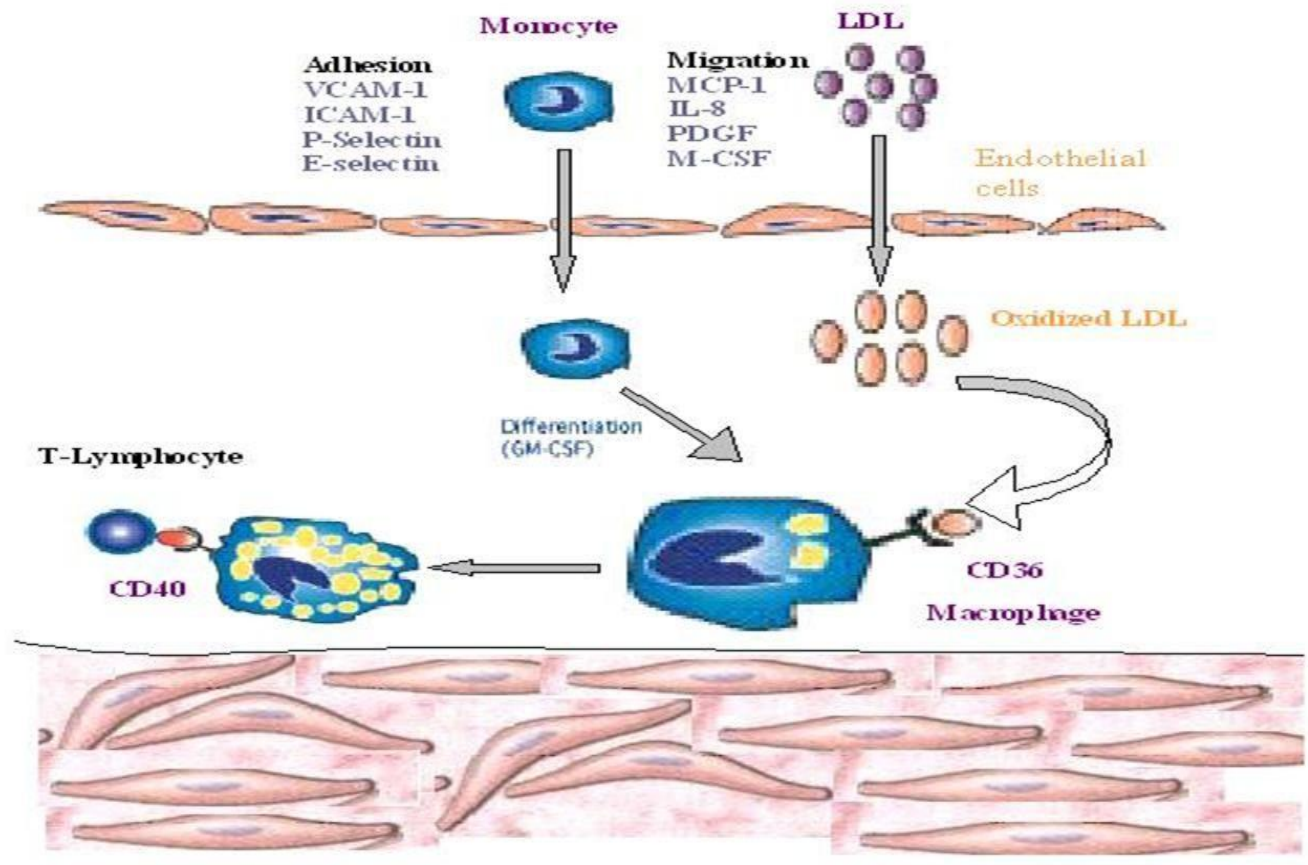

Figure 1: Atherogenesis- migration of molecules and foam cell formation

$\mathrm{M}-\mathrm{CSF}=$ macrophage colony stimulating factor; $\mathrm{MCP}-1=$ monocyte chemotactic protein 1 ; ICAM-1= intercellular adhesion molecule 1; VCAM-1= vascular cell adhesion molecule 1; PDGF=platelet derived growth factor;

GM-CSF=Granulocyte macrophage colony stimulating factor LDL= low density lipoprotein

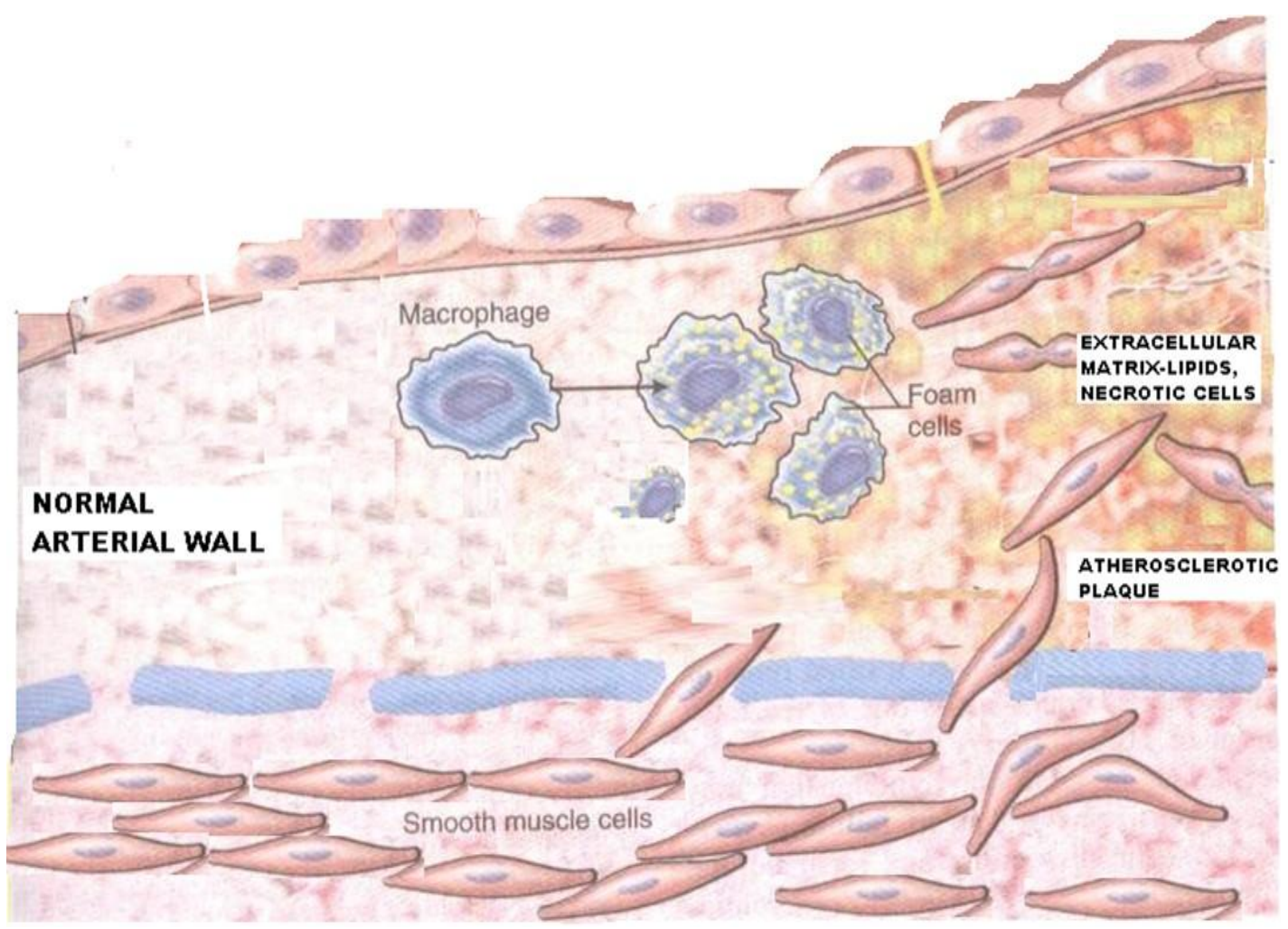

Figure 2: Atherosclerotic plaque 
lar endothelial cells by binding surface receptors such as receptor for AGE (RAGE). The diabetic state also promotes dyslipidaemia and oxidative stress. ${ }^{18}$ Obesity not only predisposes to insulin resistance and diabetes, but also contributes to atherogenic dyslipidemia. Adipose tissue can also synthesize proinflammatory cytokines TNF- $\alpha$ and IL- $6 .{ }^{19}$

Dyslipidaemia observed in these disease states which is in the form of increased very low density lipoprotein (VLDL), intermediate density lipoprotein and low density lipoprotein (LDL) as well as decreased high density lipoprotein (HDL) also has direct atherogenic potential. Homocysteine is toxic to endothelium and is prothrombotic, and it increases collagen production and decreases the availability of nitric oxide. ${ }^{16}$ Several reports have shown a correlation between the incidence of atherosclerosis and infections. ${ }^{20}$

\section{EVOLUTION OF PATHOGENIC MECHANISMS}

\section{Dyslipidaemia}

Understanding of the pathophysiology of atherosclerosis traditionally rested on studying the role of cholesterol, cholesterol trafficking lipoproteins, and cellular and molecular mechanisms regulating cholesterol metabolism. $^{21,22}$ VLDL and LDL are now known to undergo oxidative modification and oxidized LDL has been shown to contribute to the atherosclerotic lesion at various levels including causation of endothelial dysfunction. In addition, some evidence suggests that beta VLDL particles may themselves activate inflammatory functions of vascular endothelial cells ${ }^{23,}{ }^{24}$. HDL protects against atherosclerosis through reverse cholesterol transport and transport of antioxidant enzymes such as plateletactivating factor acetylhydrolase and paraoxonase. $^{2}$

Thus, the role of modified lipoproteins in the pathogenesis of atherosclerosis has been well appreciated and understanding of the molecular pathways that regulate cholesterol metabolism enabled development of drug therapies that have proved to be effective in reducing clinical events in broad categories of individuals. However, it was observed that a substantial proportion of cardiovascular events occur in individuals without demonstrable dyslipademia. This led to further probing of the pathogenesis of atherosclerosis which resulted in better understanding of the molecular mechanisms underlying the disease.

\section{Oxidative stress and atherosclerosis:}

Several studies have examined the potential role of oxidative stress in atherogenesis. Initially, it was thought that the role of oxidative stress in atherosclerosis is mainly oxidative modification of LDL in the arterial wall by reactive oxygen species (ROS). Common risk factors for atherosclerosis like hypercholesterolemia, diabetes mellitus, arterial hypertension, smoking, and age increase the production of free ROS, not only from the endothelial cells, but also from the smooth muscle cells and the adventitial cells ${ }^{25}$. Initially it was believed that if LDL oxidation is prevented by using antioxidants, atherosclerosis and its complications can be prevented clinically. Many clinical trials were also conducted but with controversial reports. This created a need to probe further into the role of oxidative stress in atherosclerosis.

Current evidence suggests that free radicals have more significant role to play in atherogenesis. They induce endothelial dysfunction, an initial and critical step in atherogenesis. The ROS induce the expression of adhesion molecules vascular adhesion molecule 1 (VCAM-1) and monocyte chemattranct protein 1 (MCP1). ${ }^{26}$ These changes may induce alterations in the structure and function of endothelial cells and contribute to the initiation of atherosclerosis. ${ }^{27}$ ROS reduce the production and consequently the bioavailability of nitric oxide (NO), leading to vasoconstriction, platelet aggregation and adhesion of neutrophils to the endothelium. ${ }^{28}$ Oxidative stress leading to increased hydrogen peroxide causes phosphorylation of tyrosine kinases, which leads to stronger binding of neutrophil 
cells on endothelium and alteration of vessel permeability. ${ }^{29}$ The interaction of superoxide with NO leads to the production of peroxynitrite, a substance less effective for the activation of guanylate cyclase and reduced bioavailability of NO. In stages of advanced atherosclerosis, despite the fact that NO production remains the same, decomposition of NO from ROS is increased. $^{30}$ Another mechanism through which hydrogen peroxide affects atherogenesis is the production of transcription factors such as nuclear factor IB (NF-IB) and activator protein 1 (AP-1), which participate in the expression of adhesion molecules. $^{31,32}$ Thus, oxidative stress contributes significantly to the inflammatory response leading to atherosclerosis.

Many of the enzymes of oxidative stress such as xanthine oxidase and nicotinamide adenine dinucleotide phosphate (NADPH) oxidase are expressed in vascular endothelial cells and contribute to the production of reactive oxygen species. In response to inflammation or endothelial cell injury, these enzymes are activated in vascular cells. $^{27}$ Glutathione (GSH) and related enzymes, such as glutathione peroxidase or glutathione transferase, occur in extracellular spaces such as plasma and are thought to play an important role in protecting the vascular system against oxidative stress.

Lundberg et $\mathrm{al}^{33}$ found glutaredoxin-1 (GRX1), the mitochondrial type of glutaredoxin, in human serum and suggested an extracellular redox system of GSH/GRX1, shown to be involved in the critical role played by vascular smooth muscle cells in the pathogenesis of atherosclerosis. The protective effects of estrogens, and also dehyroepiandrosterone appear to be mediated by their effects on oxidative stress. ${ }^{34}$

The above discussion helps us to appreciate that our understanding of contribution of oxidative stress to atherogenesis is not yet complete and there is scope for better understanding and novel therapeutic applications in this area.

\section{Inflammmation and atherosclerosis}

The basic mechanism of plaque formation is now known to be due to the inflammatory response to endothelial injury. The evidence of inflammation in formation of atherosclerotic plaque comes from observation of lesions at various stages of development which are typical of an inflammatory response. The atherosclerotic lesion does not occur when endothelium is normal but occurs only as a response to injured endothelium, also known as endothelial dysfunction. There is involvement of leukocytes, connective tissue cells (smooth muscle cells) and extracellular matrix (collagen). The role of inflammatory cytokines is now well established. The continued inflammatory response is also able to explain the complications that occur i.e., the plaque rupture and thrombosis. ${ }^{2,15}$ The role of inflammation in atherosclerosis has been mostly derived from studies in animal models using apolipoprotein E (apo E -/ -) or LDL receptor (LDL-R -/-) deficient mice. Mice with apo $\mathrm{E}-/-$ showed massively increased cholesterol levels and developed accelerated atherosclerosis with extensive lipid deposition on major arteries. $^{35}$

The knowledge gained from the link between inflammation and atherosclerosis resulted in yielding predictive and prognostic information of considerable clinical utility. The role of inflammatory markers such as CRP in predicting cardiovascular risk has been well estab- lished. ${ }^{36}$ These new insights into inflammation in atherosclerosis not only helped in increasing the understanding of the disease, but also have practical clinical applications in risk stratification and targeting of therapy. The profound anti inflammatory actions of statins, acetyl salicylic acid and angiotensin converting enzyme inhibitors may partly be responsible for their stroke prevention effects. ${ }^{37}$

\section{Immunity and atherosclerosis}

The major leukocytes involved include 
monocyte and lymphocytes rather than granulocytes. An important finding has been that the atherosclerotic plaques were heavily infiltrated by $\mathrm{CD} 4+\mathrm{T}$ lymphocytes $^{38}$. This finding of immune response mediating cells in the atherosclerotic lesions led to the hypothesis that the inflammatory response observed in atherosclerosis is that of immune mediated inflammatory response. During recent years, experiments in gene targeted mice have provided considerable evidence in support of the role of immune mechanisms in atherosclerosis.

Atheroma formation is not contributed by macrophages alone, but also by $\mathrm{T}$-cells, dendritic cells and mast cells ${ }^{3}$. Entry of Tlymphocytes into the arterial intima is facilitated by their binding to adhesion molecules such as VCAM -1. Once within the arterial intima, T-cells may become activated by encountering antigens such as Ox-LDL and begin to secrete cytokines, which further can influence macrophage activity. Activated macrophages express class II histocompatibility antigens such as HLA-DR that allows them to present antigens to T-lymphocytes. T-cells are activated when they bind to the antigen processed and presented by macrophages and this activation results in the secretion of cytokines, including interferon $\gamma($ IFN- $\gamma$ ) and tumor necrosis factor (TNF- $\alpha$ and- $\beta$ ), that amplify the inflammatory response ${ }^{16}$.Thus, cell mediated immune response may also be involved in atherogenesis and both CD4 and CD8+ Tcells are present in the lesions at all stages $^{39}$. Further evidence of immune activation in atherosclerotic lesions is provided by the up regulated expression of an immuno regulatory molecule CD40 ligand and its receptor CD40 in these lesions. Both molecules are expressed by macrophages, T-cells, endothelium and smooth muscle cells ${ }^{40}$.

The vascular endothelial cells and smooth muscle cells have been shown to be important targets for inflammatory cytokines and produce significant amounts of cytokines themselves on stimulation. ${ }^{41,42}$
Dendritic cells play an important role as specialized antigen presenting cells required for the activation of naive T-cells and the development of antigen specific $\mathrm{T}$ cell mediated immune responses. ${ }^{43}$ Potential candidate T-cell antigens in atherosclerosis involve both autoantigens as well as microbial derived antigens (Table 2). Antigen presentation to T-cells promotes generation of antigen specific pathogenic and / or regulatory T-cells. ${ }^{43}$ Macrophages are important cells in mediating inflammation, innate and adaptive immune responses all of which are important in atherogenesis. ${ }^{44}$ Macrophages take up modified lipoproteins through scavenger receptors. The process is regulated by cytokines and scavenger receptor A (SR-A) can also internalize antigens which are routed for presentation to T-cells. ${ }^{45,46}$ Scavenger receptors may act as an important link between innate and adaptive immunity by binding foreign antigens and initiating their transfer to antigen processing as well as degradative compartments. Most of the T-cells in atherosclerotic lesions are CD 3+ CD4+ Tcell receptor (TCR) $\alpha \beta^{+}$cells. ${ }^{47,48}$ Many are largely of $\mathrm{T}$ helper (Th1) subtype, which secrete IFN- $\gamma$, IL- 2 and TNF- $\alpha$ and- $\beta$, which are important in causing macrophage activation, vascular activation and inflammation. $^{49}$ Th1 differentiation is stimulated by cytokine IL -12 , produced by dendritic cells and macrophages / monocytes. ${ }^{50}$ Osteopontin, also known as early T-lymphocyte activation protein is needed for Th1 responses and promotes IL12 expression and granuloma formation ${ }^{51}$. It has been proposed that IFN- $\gamma$ producing T-cells could play an important role in plaque destabilization by reducing the fibrous cap. ${ }^{52,53}$ Th1 cells could also participate in the proinflammatory cytokine cascade, for instance, IFN- $\gamma$ produced by Th1 cells stimulate IL-1 secretion by macrophages, IL-1 further stimulates SMC to produce IL-6, ${ }^{54}$ which is a mediator present in atherosclerotic lesion. The cascade also involves secretion of $\mathrm{CRP}^{55}$ and it has been shown that even a modestly 
increased CRP was found to be a risk factor for coronary heart disease in healthy, middle aged men. ${ }^{56}$

Th2 cytokines such as IL-4, IL-5 and IL-10 are less abundant than cytokines of the Th1 subtype in end stage human lesions. ${ }^{49}$ Cytokines of Th1 and Th2 are cross regulatory in that IL -10 acts as an inhibitor of Th1 pathway and IL-12 is a Th2 inhibitor. ${ }^{44} \mathrm{~A}$ third helper cell called Th3 has also been described. Activated Th3 cells produce transforming growth factor- $\beta$ (TGF- $\beta$ ), another cytokine which is anti inflammatory in nature, stimulates collagen synthesis and is fibrogenic. Several different cell types, including macrophages, SMCs and Th3 cells can express TGF- $\beta$ which might be important for plaque stabilization. ${ }^{44}$

Additional cells in atherosclerotic lesions are CD8+ $\mathrm{T}$-cells, a subpopulation of $\mathrm{T}$ cells with cytotoxic activity (cytotoxic $\mathrm{T}$ - cells). These are activated when antigens are presented in association with class I major histocompatibility complex (MHC). ${ }^{44}$

CD8+ T-cells have been proposed to cause some of the wide spread apoptosis that is associated with atherosclerosis ${ }^{57}$ though however, apoptosis can also be induced by other factors such as reactive oxygen and nitrogen species. $^{58}$ Thus, activation of $\mathrm{CD} 4+$ as well as CD8+ Tcells can lead to cell death in lesions.CD8+ T-cells respond to antigens by their cytotoxic activity and also by secretion of cytokines in a manner parallel to that observed for Th1 and Th2 cells. ${ }^{44}$ Other types of lymphocytes such as B cells and Natural killer (NK) cells are less frequently found in advanced human lesions, but B-cell infil-

Table 2: Various antigens incriminated in immune response of atherogenesis

\begin{tabular}{ll}
\hline Autoantigens & Microbial antigens \\
\hline Oxidised low-density lipoprotein & Porphyromonas gingivalis \\
Beta2glycoprotein1 & Chlamydia pneumoniae \\
Lipoprotein (a) & Bacteroides forsynthus \\
Lipoprotein-lipase & Streptococcus mutans \\
Advanced glycation-end products & Helicobacter pylori \\
Heat-shock proteins & Escherichia coli \\
Collagen & Enterovirus \\
Fibrinogen & Cytomegalovirus \\
& Viperin \\
\hline
\end{tabular}

trates may occur in prominence in the adventitia and the peri adventitial connective tissue. ${ }^{44,59}$

Thus the imbalance between pro- and antiinflammatory immune responses appears to be responsible for the development of atherosclerosis. The Th1 response is considered to be proinflammatory and $\mathrm{Th} 2$ response is considered to be antiinflammatory. The regulation of the balance between Th1 and Th2 immune re- sponses appears to be controlled by another T-cell subset referred to as regulatory T-cells (Tregs). Th2 responses are also recognized in advanced stages of atherosclerosis, and there seems to be a shift of the immune response towards a Th2 type, indicating that in late stages the immune system is trying to overcome the proinflammatory damage. The balance between Th 1 and Th 2 responses decides the plaque formation and stability. ${ }^{60}$ 


\section{Clinical applications}

The ultimate aim of understanding the mechanisms is to develop markers of disease and design novel therapeutic modalities for the prevention and regression of atherosclerotic lesions. Today we have a separate set of cardiovascular risk markers known as "novel"or "nontraditional" in routine clinical use based on the current understanding of atherosclerotic mechanisms (Table-3). Examples include high sensitivity CRP (hsCRP), homocys-

Table 3: Traditional and novel risk factors for atherosclerotic vascular disease

\begin{tabular}{ll}
\hline Traditional & Novel \\
\hline Dyslipidaemia & C-reactive protein \\
Hypertension & Interleukins (e.g. , interleukin-6) \\
Smoking & Fibrinogen \\
Diabetes & Lipoprotein (a) \\
& Apolipoproteins A1 and B \\
& Oxidized low density lipoprotein \\
& Homocysteine \\
& Uric acid \\
& Insulin Resistance \\
\hline
\end{tabular}

teine and fibrinogen. Lipid lowering therapy had been a major achievement on the therapeutic front. Antioxidant therapy has been used with controversial outcomes. Understanding the triggers of endothelial dysfunction led to use of antiplatelet drugs and vitamins to lower homocysteine levels. Some of the drugs like statins and some antiplatelet drugs have been shownto have anti-inflammatory effect also. Now with reasonably good understanding of the immune mechanisms in the formation of atherogenic plaque, vaccines and immunomodulatory efforts are under development.

\section{ACKNOWLEDGEMENT}

The authors acknowledge the help rendered by Dr Aparna R. Bitla, Associate Professor for critically evaluating the manuscript and for her valuable suggestions. Ms. G. Sarvari (M.Sc student)'s help in preparing the figures is thankfully acknowledged. The authors also wish to place on record their sincere thanks to the postgraduate students of the Department for their secretarial assistance.

\section{REFERENCES}

1. Lipsky PE. Rheumatoid arthritis. In: Fauci AS, Braunwald E, Kasper DL, Hausar SL, Longo DL,
Jameson JL, et al editors. Harrison's principles of internal medicine. 17th edition. Philadelphia: McGraw-Hill companies, Inc; 2008.p. 2083-86.

2. Libby P, Ridker PM, Maseri A. Inflammation and atherosclerosis. Circulation 2002;105:1135-43.

3. Szmitko P, Wang C, Weisel R, de Almeida J, Anderson T, Verma . New Markers of inflammation and endothelial cell activation. Part I. Circulation 2003; 108:1917-23.

4.Verma S, Anderson TJ. Fundamentals of endothelial function for the clinical cardiologist. Circulation 2002;105:546-9.

5. Bombeli , Schwartz B, Harlan J. Adhesion of activated platelets to endothelial cells: evidence for a GPIIbIIIa-dependent bridging mechanism and novel roles for endothelial intercellular adhesion molecule 1 (ICAM-1), $\alpha_{\mathrm{v}} \beta_{3}$ integrin, and GPIb $\alpha$. J Exp Med 1998;187:329-39.

6. Collins T, Cybulsky MI. NF-кB: pivotal mediator or innocent bystander in atherogenesis? J Clin Invest 2001; 107:255-64.

7. Chen M, Masaki T, Sawamura T. LOX-1, the receptor for oxidized low-density lipoprotein identified from endothelial cells: implications in endothelial dysfunction and atherosclerosis. Pharmacol Ther 2002;95:89-100.

8. Verma S, Li S, Badiwala M, Weisel R, Fedak P, Li R, et al. Endothelin antagonism and interleukin6 inhibition attenuate the proatherogenic effects of C- reactive protein. Circulation 2002;105:1890-6.

9.Kaplanski G, Marin V, Fabrigoule M, Boulay V, Benoliel AM, Bongrand $\mathrm{P}$, et al. Thrombinactivate human endothelial cells support monocyte adhesion invitro following expression of intercellular adhesion molecule-1 (ICAM-1;CD54) 
and vascular cell adhesion molecule-1 (VCAM -1; CD106). Blood 1998;92:1259-67.

10. Schonbeck U, Lippy P. CD40 signaling and plaque instability. Circ Res 2001;89:1092-103.

11. Kunjathoor VV, Febbraio M, Podrez EA, Moore KJ, Andersson L, Koehn S, et al. Scavenger receptors class A-I/II and CD36 are the principal receptors responsible for the uptake of modified low density lipoprotein leading to lipid loading in macrophages. $\mathrm{J}$ Biol Chem 2002;277:49982-8.

12. H Yoshida, N Kondratenko, S Green, D Steinberg, O Quehenberger, et al. Identification of the lectin-like receptor for oxidized low-density lipoprotein in human macrophages and its potential role as a scavenger receptor. Biochem J 1998;334:9-13.

13. Libby P. Inflammation in atherosclerosis. Nature 2002;420:868-74.

14. Porreca E, Di Febbo C, Reale M, Castellani ML, Baccante G, Barbacane R, et al . Monocyte chemotactic protein 1 (MCP-1) is a mitogen for cultured rat vascular smooth muscle cells. J Vasc Re 1997;34:58-65.

15. Fan J, Watanabe T. Inflammatory reactions in the pathogenesis of atherosclerosis J Atheroscler Throm 2003;10:63-71.

16. Ross R. Atherosclerosis-An inflammatory disease. N Engl J Med 1999;340:115-2.

17. Schmidt A, Yan S, Wautier J, Stern . Activation of receptor for advanced glycation end products: a mechanism for chronic vascular dysfunction in dia- betic vasculopathy and atherosclerosis. Circ Res 1999; 84:489-97.

18. Baynes JW, Thorpe SR. Role of oxidative stress in diabetic complications: a new perspective on an old paradigm. Diabetes 1999;48:1-9.

19. Yudkin JS, Stehouwer CD, Emeis JJ, Coppack SW. C- reactive protein in healthy subjects: associations with obesity, insulin resistance, and endothelial dysfunction: a potential role for cytokines originating from adipose tissue? Arterioscler Thromb Vasc Biol 1999;19:972-8.

20. Libby P, Egan D, Skarlatos S. Roles of infectious agents in atherosclerosis and restenosis: an assessment of the evidence and need for future research. Circulation 1997;96:4095-103.

21. Libby P. Inflammation and cardiovascular disease mechanisms. Am J Clin Nutr 2006;83:456S - 460S.

22. Tabas I. Consequences of cellular cholesterol accumulation: basic concepts and physiological implications. J Clin Invest 2002;110:905-11.

23. Dichtl W, Nilsson S, Goncalves I, Ares MP, Banfi C, Calara F, et al. Very low density lipoprotein activates nuclear factor- $\kappa \mathrm{B}$ in endothelial cells. Circ Res 1999;84: 1085-94.

24. Mackness MI, Mackness B, Durrington PN, Fogelman AM, Berliner J, Lusis AJ, et al. Paraoxonase and coronary heart disease. Curr Opin Lipidol 1998;9:319-24.
25. Gozin A, Franzini E, Andrieu V, Da Costa L, Rollet-Labelle E, Pasquier C. Reactive oxygen species activate focal adhesion kinase, paxillin and p130cas tyrosine phosphorylation in endothelial cells. Free Radic Biol Med 1998;25: 1021-32.

26. Ganji SH, Qin S, Zhang L, Kamanna VS, Kashyap ML. Niacin inhibits vascular oxidative stress, redox-sensitive genes, and monocyte adhesion to human aortic endothelial cells. Atherosclerosis 2009;202: 68-75.

27. Vasquez-Vivar J, Kalyanaraman B, Hogg N, Martásek P, Masters BS, Karoui H, et al. Superoxide generation by endothelial nitric oxide synthase: The influence of cofactors. Proc Natl Acad Sci 1998; 95: 9220-5.

28. Vepa S, Scribner WM, Parinandi NL, English D, Garcia JG, Natarajan V. Hydrogen peroxide stimulates tyrosine phosphorylation of focal adhesion kinase in vascular endothelial cells. Am J Physiol 1999;277: L150-L158.

29. Bourcier T, Sukhova G, Libby P. The nuclear factor kappa-B signalling pathway participates in disregulation of vascular smooth muscle cells in vitro and in human atherosclerosis. J Biol Chem 1997;272:15817-24.

30. Hsich E, Segal BH, Pagano PJ, Rey FE, Paigen B, Deleonardis J, et al. Vascular effects following homozygous disruption of p47(phox): An essential component of

NADPH oxidase. Circulation 2000;101:1234-6.

31. Vogiatzi G, Tousoulis D, Stefanadis C. The Role of Oxidative Stress in Atherosclerosis. Hellenic J Car-diol 2009; 50: 402-9.

32. Kanda M, Ihara Y, Murata H, Urata Y, Kono T, Yodoi J, et al. Glutaredoxin modulates plateletderived growth factor-dependent cell signaling by regulating the redox status of low molecular weight protein-tyrosine phosphatase. J Biol Chem 2006;281: 28518-28.

33. Lundberg M, Fernandes AP, Kumar S, Holmgren A.Cellular and plasma levels of human glutare- doxin 1 and 2 detected by sensitive ELISA systems. Biochem Biphys Res Commun 2004;319:801-9.

34. Kondo T, Hirose M, Kageyama K. Roles of oxidativestress and redox regulation in atherosclerosis. J Atheroscle Thromb 2009;16:5328.

35. Moghadasian MH, McManus BM, Nguyen LB, Shefer S, Nadji M,Godin DV, et al. Pathophysiology of apolipoprotein E deficiency in mice: relevance to apo E-related disorders in humans. FASEB J 2001;15:2623-30.

36. Daniel G. Hacka, Sonia S. Anan. Emerging Risk Factors for Atherosclerotic Vascular Disease. JAMA 2003;290:932-40.

37. Stoll G, Bendszus M. Inflammation and atherosclerosis: novel insights into plaque formation and destabilization. Stroke 2006;37:1923-32. 
38. Stemme S, Faber B, Holm J, Wiklund O, Witztum JL, Hansson GK. T lymphocytes from human atherosclerotic plaques recognize oxidized low density lipoprotein. Proc Natl Acad Sci 1995;92:3893-7.

39. Hansson GK, Jonasson L, Seifert PS, Stemme $\mathrm{S}$. Immune mechanisms in atherosclerosis. Arterioscler Thromb Vasc Biol 1989;9:567-78.

40. Mach F, Schönbeck U, Bonnefoy JY, Pober JS, Libby P. Activation of monocyte/macrophage function related to acute atheroma complication by ligation of CD40: induction of collagenase, stromelysin, and tissue factor. Circulation 1997;96:396-9.

41. Pober JS, Collins T, Gimbrone MA Jr, Cotran RS, Gitlin JD, Fiers W, et al. Lymphocytes recognize human vascular endothelial and dermal fibroblast Ia antigens induced by recombinant immune interferon. Nature 1983;305:726-9.

42. Warner SJ, Auger KR, Libby P. Interleukin-1 induces interleukin-1, II: recombinant human interleukin-1 induces interleukin-1 production by adult human vascular endothelial cells. J Immunol 1987;139:1911-7.

43. Mallat Z, Taleb S, Ait-Oufella H, Tedgui A. The role of adaptive $\mathrm{T}$ cell immunity in atherosclerosis. J Lipid Re 2009;50:S364-S369.

44. Hansson GK. Immune mechanisms in atherosclerosis. Arterioscler Thromb Vasc Biol 2001;21:1876-90.

45. Abraham R, Choudhury A, Basu SK, Bal V, Rath S. Disruption of $\mathrm{T}$ cell tolerance by directing a self antigen to macrophage-specific scavenger receptors. J Immunol 1997;158:4029-35.

46. Nicoletti A, Caligiuri G, Törnberg I, Kodama $\mathrm{T}$, Stemme S, Hansson GK. The macrophage scavenger receptor type A directs modified proteins to antigen presentation. Eur $\mathrm{J}$ Immunol 1999;29:512-21.

47. Jonasson L, Holm J, Skalli O, Bondjers G, Hansson GK. Regional accumulations of $\mathrm{T}$ cells, macrophages, and smooth muscle cells in the human atherosclerotic plaque. Arterioscler Thromb Vasc Biol 1986;6:131-8

48. Stemme S, Holm J, Hansson GK. T lymphocytes in human atherosclerotic plaques are memory cells expressing CD45RO and the integrin VLA-1. Arterioscler Thromb Vasc Biol 1992; 12:206-11.

49. Frostegard J, Ulfgren AK, Nyberg P, Hedin
U, Swedenborg J, Andersson U, et al. Cytokine expression in advanced human atherosclerotic plaques: dominance of pro-inflammatory (Th1) and macro-phage-stimulating cytokines.

Atherosclerosis 1999;145:33-43

50. Uyemura K, Demer LL, Castle SC, Jullien D, Berliner JA, Gately MK,et al. Cross-regulatory roles of interleukin (IL)-12 and IL-10 in atherosclerosis. J Clin Invest 1996; 97: 2130-8.

51. Ashkar S, Weber GF, Panoutsako- poulou V, Sanchirico ME, Jansson M, Zawaideh S, et al. Eta-1 (osteopontin): an early component of type-1 (cellmediated) immunity. Science 2000; 287:860-4.

52. Hansson GK, Libby P. The role of the lymphocyte.In: Fuster V, Ross R, Topol EJ, editorss. Atherosclerosis and coronary artery disease. Philadelphia: Lippincott-Raven Publishers; 1995.p. 557- 68

53. Libby P. Molecular bases of the acute coronary syndromes. Circulation 1995; 91:2844-50.

54. Loppnow H, Libby P. Proliferating or interleukin 1-activated human vascular smooth muscle cells secrete copious interleukin 6. J Clin Invest 1990;85: 731-8.

55. Gewurz H, Zhang XH, Lint TF. Structure and function of the pentraxins. Curr Opin Immunol 1995; 7: 54-64.

56. Ridker PM, Rifai N, Stampfer MJ, Hennekens $\mathrm{CH}$. Plasma concentration of interleukin- 6 and the risk of future myocardial infarction among apparently healthy men. Circulation 2000;101:1767-72.

57. Geng YJ, Henderson LE, Levesque EB, Muszynski M, Libby P. Fas is expressed in human atherosclerotic intima and promotes apoptosis of cytokine-primed human vascular smooth muscle cells. Arterioscler Thromb Vasc Biol 1997; 17:2200-8.

58. Geng YJ, Wu Q, Muszynski M, Hansson GK, Libby P. Apoptosis of vascular smooth muscle cells induced by in vitro stimulation with interferon- $\gamma$, tumor necrosis factor- $\alpha$, and interleukin- $1 \beta$. Arterioscler Thromb Vasc Biol 1996;16:19-27

59. Parums DV, Chadwick DR, Mitchinson MJ. The localization of immunoglobulin in chronic periaortitis. Atherosclerosis 1986; 61: 117-123. 60. Milioti N, Bermudez-Fajardo A, Penichet ML, Oviedo-Orta E. Antigen Induced Immunomodulation in the Pathogenesis of Atherosclerosis. Clin Dev Immuno 2008;2008:7235-39. 